\title{
11 p13 Deletion, Wilms' tumour, and aniridia: unusual genetic, non-ocular and ocular features of three cases
}

Véronique Jotterand, Hélène $M$ Boisjoly, Carmen Harnois, Pierre Bigonesse, Rachel Laframboise, Richard Gagné, André St-Pierre

\begin{abstract}
Three cases of Wilms' tumour and sporadic aniridia were followed up for periods ranging from 32 months to seven years. All had a deletion of the short arm of the eleventh chromosome 11p13, including one case with mosaicism, a cytogenetic feature that has not been previously described in the Wilms' tumour and sporadic aniridia association. Unusual non-ocular features found in all patients included tracheomalacia and delayed closure of the anterior fontanelle. In two cases tracheomalacia was responsible for respiratory distress after general anaesthesia. Wilms' tumour developed bilaterally in one patient and on the isthmus of a horseshoe kidney in another patient. In addition to the more commonly observed ocular features the presence of a corneal pannus was noted before 38 months of age in all patients and as early as 17 months in one case. An iridocorneal adherence with an overlying corneal opacity (presumably related to abnormal developmental cleavage of the anterior segment) was noted in one eye only of the mosaicism case.
\end{abstract}

Congenital aniridia can be sporadic or inherited as an autosomal dominant, ${ }^{12}$ rarely as an autosomal recessive disease. ${ }^{3}$ The majority of cases of aniridia with deletion $11 \mathrm{p} 13$ are sporadic. Approximately $68 \%$ of patients who have deletion of chromosome 11 and aniridia will develop Wilm's tumour before age 3 years. ${ }^{4}$ There are now over 65 reported cases of the 11 p13 depletion, Wilms' tumour, aniridia association..$^{4-9}$ In addition affected children often have genitourinary malformations, craniofacial dysmorphism, and developmental delay. ${ }^{6}$ In this paper we summarise the genetic, non-ocular, and ocular manifestations and discuss the more unusual features found in three patients with 11 p13 deletion, Wilms' tumour, aniridia association.

\section{Features of the cases}

The genetic, non-ocular, and ocular features of three cases of 11 p13 deletion, Wilms' tumour, and aniridia are summarised in Tables 1,2 , and 3. Two girls and one boy, with normal family and pregnancy histories, were referred during their first months of life for diagnosis and follow-up aniridia. The visual function of these children, assessed by electrophysiological testing, has previously been described. ${ }^{10}$ Cases 1 and 2 were followed up for seven years and their latest corrected visual acuities are $6 / 30$ and $6 / 60$ respectively.

GENETIC FEATURES (TABLE 1)

All the mothers had previously given birth to normal children. High resolution chromosomal banding analyses were performed in circulating white blood cells obtained from all cases and their parents as well as in Wilms' tumour cells obtained from cases 1 and 3. The parental chromosomes were normal. The children's white blood cells and Wilms' tumour cells presented a deletion of the short arm of the 11th chromosome with an interstitial deletion $11 \mathrm{p} 13$. Unexpectedly, only eight of 16 metaphases (50\%) studied in the tumour cells of case 3 had the $11 \mathrm{pl}$ deletion (Fig 1). The study of 34 metaphases in her white blood cells also demonstrated mosaicism with 23 normal cells $(68 \%)$ and 11 abnormal cells (32\%).

NON-OCULAR FEATURES (TABLE 2)

Facial dysmorphism of cases 1 and 2 was noticeable and similar (Fig 2). In case 3 facial dysmorphism was milder, with short downward slanted palpebral fissures as the only striking feature. All parents noticed that their child presented an unusual inspiratory stridor, especially after feeding or when lying supine. Tracheomalacia was diagnosed by direct visualisation with a laryngoscope in our three cases, and caused respiratory distress following general anaesthesia in cases 1 and 3. Another unusual

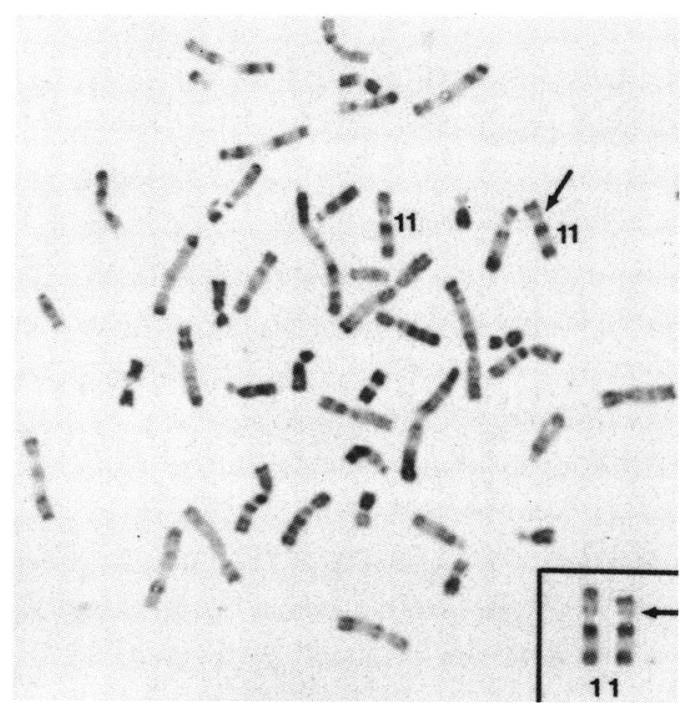

Figure 1 Case 3. Mosaicism (46, xx/46, xx, del llp13). 
Table 1 Genetic features

\begin{tabular}{lllll}
\hline $\begin{array}{l}\text { Case } \\
\text { no. }\end{array}$ & Sibship & $\begin{array}{l}\text { Mother's age } \\
\text { (years) at birth }\end{array}$ & $\begin{array}{l}\text { Cytogenetic studies: } \\
\text { parents }^{\star}\end{array}$ & $\begin{array}{l}\text { Cytogenetic studies: } \\
\text { child }^{\star}\end{array}$ \\
\hline 1 & 2 & 27 & Normal & del $11 \mathrm{p} \mathrm{13}$ \\
2 & 4 & 32 & Normal & del 11 p 13 \\
3 & 3 & 29 & Normal & $\begin{array}{c}50 \% \text { mosaicism } \\
60 \% \text { nol leucocytes }\end{array}$ \\
& & & & $68 \%$ normal Wilms tumour cells \\
\hline
\end{tabular}

$\star$ The cytogenetic studies were done on circulating white blood cells of parents and children. Except for case 2, cytogenetic studies were also done on Wilms' tumour cells.

Table 2 Non-ocular features

\begin{tabular}{|c|c|c|c|c|}
\hline $\begin{array}{l}\text { Case } \\
\text { no. }\end{array}$ & $\begin{array}{l}\text { Facial } \\
\text { dysmorphism }\end{array}$ & Tracheomalacia & $\begin{array}{l}\text { Age (months) at } \\
\text { anterior fontanelle } \\
\text { closureł }\end{array}$ & $\begin{array}{l}\text { Wilms' tumour location } \\
\text { and age at diagnosis } \\
\text { (months) }\end{array}$ \\
\hline $\begin{array}{l}1 \\
2 \\
3\end{array}$ & $\begin{array}{l}\text { Severe } \\
\text { Severe } \\
\text { Mild }\end{array}$ & $\begin{array}{l}\text { Present } \dagger \\
\text { Present } \\
\text { Present } \dagger\end{array}$ & $\begin{array}{l}33 \\
26 \\
24\end{array}$ & $\begin{array}{l}\text { Unilateral, } 29 \\
\text { Isthmus of horseshoe kidney, } 10 \\
\text { Bilateral, } 8\end{array}$ \\
\hline
\end{tabular}

*The dysmorphic features included a long face, downward slanted palpebral fissures, a stubby nose, low set ears, a poorly demarcated long philtrum, and a thin superior lip. TThese children suffered respiratory distress following anaesthesia. $¥$ The anterior fontanelle normally closes between 10 and 18 months of age.

Table 3 Ocular features ${ }^{\star}$

\begin{tabular}{|c|c|c|c|c|}
\hline $\begin{array}{l}\text { Case } \\
\text { no. }\end{array}$ & $\begin{array}{l}\text { Age (months) } \\
\text { at appearance } \\
\text { of corneal } \\
\text { pannus }\end{array}$ & $\begin{array}{l}\text { Duration (months) } \\
\text { of contact lens } \\
\text { weart }\end{array}$ & $\begin{array}{l}\text { Location of } \\
\text { polar cataracts }\end{array}$ & Unusual ocular features \\
\hline $\begin{array}{l}1 \\
2 \\
3\end{array}$ & $\begin{array}{l}38 \\
32 \\
17\end{array}$ & $\begin{array}{l}33 \\
3 \\
\text { Not fitted }\end{array}$ & $\begin{array}{l}\text { Anterior OU } \\
\text { Posterior OU } \\
\text { Posterior OS }\end{array}$ & $\begin{array}{l}\text { None } \\
\text { Tilted optic discs } \\
\text { Iridocorneal adherence OS } \\
\quad \text { Localised absence of lens zonules } \mathrm{O}\end{array}$ \\
\hline
\end{tabular}

^All cases had foveal hypoplasia and normal intraocular pressures. $†$ Contact lenses with artificial pupils worn during daytime.

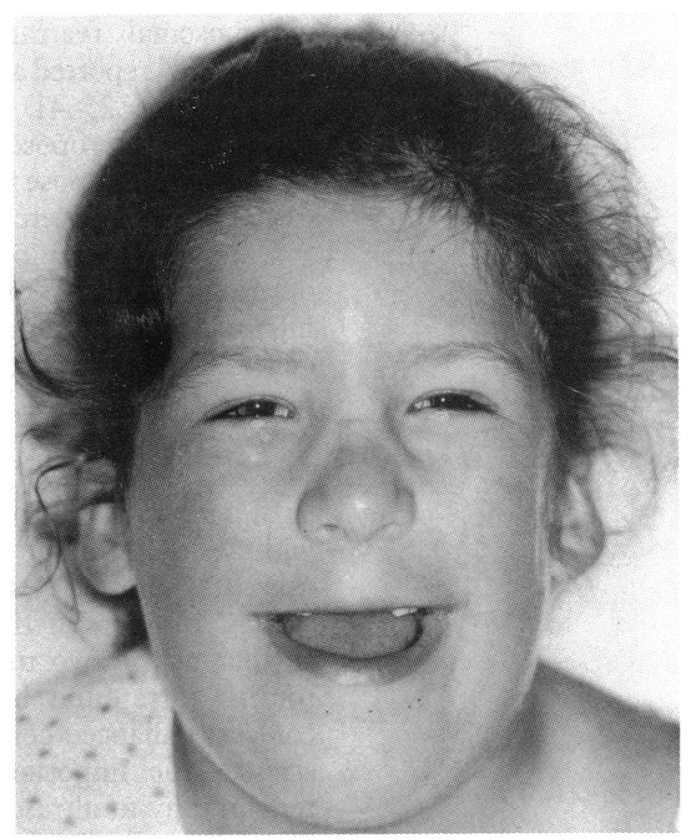

Figure 2 Case 1. Typical facial dysmorphism with a long face, downward slanted palpebral fissures, a stubby nose, low set ears, a poorly demarcated long philtrum, and a thin superior lip.

was found to be non-functional on intravenous urography at the age of 22 months. A recurrent tumour was found in the right kidney at the age of 25 months, and the child died at 32 months of age.

\section{OCULAR FEATURES (TABLE 3)}

All the children had foveal hypoplasia, polar cataracts (exceptionally, the cataract was unilateral in case 3), and normal intraocular pressures. Only case 1 wore contact lenses with artificial pupils during daytime on a regular basis for a significant amount of time. At age 38 months a peripheral inferior corneal pannus was noted for the first time, measuring $1.5 \mathrm{~mm}$ in width and progressing to $2.0 \mathrm{~mm}$ during the following two years. In case 2 a $1.0 \mathrm{~mm}$ peripheral inferior corneal pannus was noted at age 32 months. By age 41 months the pannus measured $2.0 \mathrm{~mm}$ wide in the left eye and $1.5 \mathrm{~mm}$ in the right eye. Tilted optic discs were also observed in this child. In case 3 a peripheral inferior corneal pannus measuring $1.0 \mathrm{~mm}$ wide was noted in both eyes at age 17 months. In addition an iridocorneal adherence, emerging from the rudimentary rim of the iris, with a paracentral corneal opacity overlying this adherence was found in the left eye only. Contralaterally the lens zonules were absent at the 10 o'clock position. kidney. An abdominal contrast-enhanced computed tomography revealed a second mass measuring $1.5 \mathrm{~cm}$ in diameter that ultrasound had failed to locate, seen at the hilum of the right kidney. Bilateral partial nephrectomies were performed. Well differentiated Wilms' tumours with no involvement of the regional nodes were found. A chemotherapeutic regimen combining actinomycin $\mathrm{D}$ and vincristine was started, but it was discontinued after four months because of renal failure and a generalised urticarial rash following vincristine treatment. The left kidney

\section{Discussion}

We have described unusual genetic, non-ocular and ocular features in three cases of the $11 \mathrm{pl}$ deletion, Wilms' tumour and aniridia association. The parents did not present genetic abnormalities. This is in accordance with the observation that in only three out of 15 reported families with a child having sporadic aniridia was one or other parent found to be a carrier of a 
chromosomal rearrangement." Shannon and colleagues ${ }^{12}$ reported a mean maternal age of 30.5 years (range 25-41 years) in the cases they reviewed and proposed that advanced maternal age might predispose to sporadic aniridia. In our case the mothers were not so old.

Our three cases support the fact that an $11 \mathrm{p} 13$ deletion associated with aniridia indicates a very high risk of development of Wilms' tumour. The genetic counselling to be offered to parents having a child with deletion mosaicism should probably be similar to that of other cases of 11 p13 deletions.

In a review of aniridia up to $36 \%$ of patients with Wilms' tumour and aniridia had bilateral tumours. ${ }^{13}$ Case 3 was found to have bilateral Wilms' tumours at the time of diagnosis. The smaller of the two tumours was not found on routine ultrasound but was detected only by contrast enhanced computed tomography. This stresses the importance of adding computed tomography to ultrasound for early detection of Wilms' tumour in these patients. Case 2 had a tumour on the isthmus of a horseshoe kidney. A case of a Wilms' tumour on a horseshoe kidney has also been described by Shannon et al. ${ }^{12}$

Tracheomalacia and delayed closure of the anterior fontanelle were found in all our cases. The clinical significance of a delayed fontanelle closure is not clear. Tracheomalacia, an insufficient cartilagious support of the trachea, can cause stridor or respiratory distress by tracheal collapse during periods of breathing efforts such as crying or exercising. ${ }^{14}$ The diagnosis of tracheomalacia is made by endoscopic examination, when a tracheal collapse of $50 \%$ or more is observed. ${ }^{15}$ The association of tracheomalacia and gastro-oesophageal reflux has been reported. ${ }^{16}$ We observed that tracheomalacia caused respiratory distress after general anaesthesia during infancy in cases 1 and 3 . Recently, at age 7 years, case 1 received an anaesthetic for an oesophageal foreign body obstruction; inspiratory stridor was again observed in the immediate postoperative period. Anaesthetists should therefore be informed of this possibility when children with aniridia are put under general anaesthesia.

The description of these cases adds new information on the time of appearance of corneal pannus in sporadic aniridia. Our observations suggest that it can appear as early as $\mathbf{1 7}$ months of age. Corneal pannus, also frequently recognised in adult autosomal dominant aniridia, ${ }^{17}$ has been found in two adolescents with Wilms' tumour and aniridia, aged 13 and 14 years respectively. ${ }^{18} 19$ The possibility that the pannus was related to contact lens wear is unlikely. The child (case 1) that wore contact lenses on a regular basis for almost three years developed a corneal pannus at a later age than the others.

We observed two unusual ocular features in case 3 that have not been previously described. An iridocorneal adherence was found in the left eye which is presumably related to abnormal developmental cleavage of the anterior segment. Even in autosomal aniridia, where iris anomalies can be variable, no such iridocorneal adherence has been described. ${ }^{26}$ Secondly, a localised absence of lens zonules was found contralaterally. No coloboma of the iris, ciliary body, or choroid accompanied this lens zonule anomaly. It is not clear whether these one-sided ocular anomalies could be a manifestation of the $11 \mathrm{p} 13$ mosaicism observed in case 3.

In conclusion, sporadic aniridia should immediately alert ophthalmologists and paediatricians to the presence of other ocular and systemic anomalies and a strong possibility of a chromosomal abnormality, specifically the deletion of band 13 of the short arm of the 11th chromosome. Prompt assessment by a high resolution karyotype should be done with any child presenting with isolated aniridia. The presence of an $11 \mathrm{p} 13$ deletion indicates a very high risk of the development of a Wilms' tumour. Every patient with this deletion should be followed by a paediatrician, geneticist, oncologist, and ophthalmologist. Care should be taken to document all other congenital abnormalities, including trachemalacia, a previously unreported feature that can be responsible for respiratory distress after general anaesthesia.

1 Ferrell RE, Chakravarti A, Hittner HM, Riccardi VM. Autosomal dominant aniridia; Probable linkage to acid phosphatase-1 locus on chromosome 2. Proc Natl Acad Sci $1980 ; 77: 1580-2$

2 Hittner HM, Riccardi VM, Ferrell RE, Borda RR, Justice J. Variable expressivity in autosomal dominant aniridia by clinical, electrophysiologic, and angiographic criteria. $A m \mathcal{F}$ Ophthalmol 1980; 89: 531-9.

3 Gillespie FD. Aniridia, cerebellar ataxia and oligophrenia. Arch Ophthalmol 1965; 73: 338-41.

4 Turleau C, De Grouchy J, Tournade M-F, Gagnadoux M-F, Junien C. Del 1 lp/aniridia complex. Report of three patients and review of 37 observations from the literature. Clinical Genetics $1984 ; 26$ : $356-2$.

5 Smith AMC, Sujansky E, Riccardi VM. Aniridia, mental retardation and genital abnormality in two patients with 46xy 11p-. Birth Defects 1977; 13: 257-265.

6 Nelson LB, Spaeth GL, Nowinski TS, Margo CE, Jackson L. Aniridia. A review Surv Ophthalmol 1984; 28: 621-42.

7 Narahara K, Kikkawa K, Kimira S, et al. Regional mapping of catalase and Wilms' tumor-aniridia, genitourinary abnormalities, and mental retardation triad loci to the chromosome segment 1lpl305p1306. Hum Genet 1984; 66: 181-185.

8 Bateman JB, Sparkes MC, Sparkes RS. Aniridia: enzyme studies in an 1lp chromosomal deletion. Invest Ophthalmol Vis Sci 1984; 25:612-6.

9 Mochon MC, Blanc JF, Plauchu H, Philip T. WAGR syndrome, Wilms' tumor, aniridia, gonadoblastoma, mental drome, Wilms' tumor, aniridia, gonadoblastoma, mental

10 Harnois C, Boisjoly HM, Jotterand V. Sporadic aniridia and Wilms' tumor: visual function evaluation of three cases. Graef Arch Clin Exp 1989; 227: 244-7.

11 Yunis JJ, Ramsay NKC. Familial occurrence of aniridiaWilms' tumor syndrome with deletion 1lp13-14. F Pediatr 1980; 96: 1027-30.

12 Shannon RS, Mann JR, Harper E, Harnden DG, Morten JEN, Herbert A. Wilms' tumor and aniridia: clinical and cytogenetic features. Arch Dis Child 1982; 57: 685-90.

13 Knudson AG, Strong LC. Mutation and cancer. A model for Wilms' tumor of the kidney. F Natl Cancer Inst 1972; 48: Wilms' tum

14 Wittenborg MH, Gyepes MT, Crocker D. Tracheal dynamics in infants with respiratory distress, stridor and collapsing trachea. Radiology 1967; 88: 653-62.

15 Campbell AH. Definition and causes of the tracheo-bronchial collapse syndrome. $B r \mathcal{F}$ Dis Chest 1967; 61: 1 .

16 Couvreur J, Grimfeid A, Tournier G, et al. La dyskinésie trachéale (trachéomalacie) chez l'enfant. Sem Hop Paris 1981; 8: 688-97.

17 Mackman G, Brightbill FS, Optiz JM. Corneal changes in aniridia. Am $\mathcal{F}$ Ophthalmol 1979; 87: 497-502.

18 Flaherty MP, Bousfield L, Sillence DO. Aniridia resulting from chromosome 11pl3 deletion (Miller's syndrome): report of a case. Australian f Ophthalmol 1984; 12:197-202.

19 Kaiser-Kupfer MI, White BJ, Papadopoulos N. Aniridia and mental retardat, White BJ, Papadopoulos $\mathrm{N}$. Aniridia and chromosome 11. Tr Am Ophth Soc 1981; 79: 276-93. 